Int. J. Electrochem. Sci., 13 (2018) $7370-7384$

International Journal of

ELECTROCHEMICAL

SCIENCE

$\underline{\text { www.electrochemsci.org }}$

\title{
Preparation of High Catalytic Activity and Low Platinum Loading Catalyst for Methanol Oxidation
}

\author{
Ying Zhao, Longwei Chen", Ye Song, and Yuedong Meng \\ Institute of Plasma Physics, Chinese Academy of Sciences, Hefei 230031, China; \\ *E-mail: 1 wchen@ipp.ac.cn \\ doi: $10.20964 / 2018.08 .55$
}

Received: 6 March 2018 / Accepted: 1 June 2018 / Published: 5 July 2018

In this paper, low platinum loading catalysts for methanol oxidation was fabricated by impregnation and reduction of inductively coupled plasma (ICP). The Pt-based supported on RGO catalysts (Pt/RGO-2) was finally obtained, which was of well dispersion, uniform sizes distribution, a stable adhesion of $\mathrm{Pt}$ nanoparticles with GO and suitable platinum crystal structure. Compared with commercial Pt/C catalysts, the catalysts $\mathrm{Pt} / \mathrm{RGO}-2$ was exhibited an improved and stable electrocatalytic activity and good tolerance towards $\mathrm{CO}$ poisoning for methanol oxidation via cyclic voltammetry $(\mathrm{CV})$ and chronoamperometry in acid medium. The electrochemically active surface area (ESCA) of the achieved catalysts reached to $1026 \mathrm{~cm}^{2} \cdot \mathrm{mg}^{-1}$, attributing to the large surface area of graphene for $\mathrm{Pt}$ nanoparticles anchoring. The forward peak anodic current density $\left(I_{f}\right)$ and the backward peak anodic current density $\left(I_{f}\right)$ of Pt/RGO-2 were measured to be $59 \mathrm{~mA} \cdot \mathrm{mg}^{-1}$ and 54 $\mathrm{mA} \cdot \mathrm{mg}^{-1}$, respectively. The ratio of the forward current to the backward current $\left(I_{f} / I_{b}\right)$ was calculated to be 1.09 .

Keywords: Pt-based catalyst; Graphene; Electrocatalyst; Methanol oxidation reaction

\section{FULL TEXT}

(C) 2018 The Authors. Published by ESG (www.electrochemsci.org). This article is an open access article distributed under the terms and conditions of the Creative Commons Attribution license (http://creativecommons.org/licenses/by/4.0/). 